\title{
A PRIMER ON CLOTHING SYSTEMS FOR COLD-WEATHER FIELD WORK
}

By Jon C. Denner

U.S. GEOLOGICAL SURVEY

Open-File Report 89-415

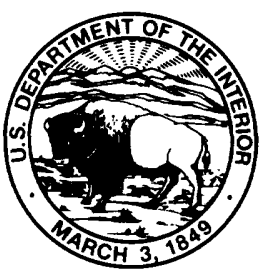

Bow, New Hampshire Revised 1993 
DEPARTMENT OF THE INTERIOR

BRUCE BABBITT, Secretary

U.S. GEOLOGICAL SURVEY

Dallas L. Peck, Director

For additional information write to:

Chief, NH-VT Office

U.S. Geological Survey

525 Clinton St.

Bow, New Hampshire 03304
Copies of this report can be purchased from: Books and Open-File Reports Section U.S. Geological Survey

Federal Center

Box 25425

Denver, Colorado 80225 


\section{CONTENTS}

Page

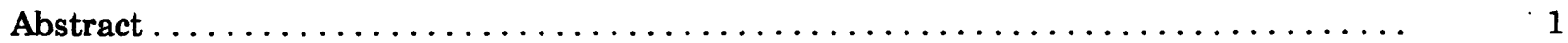

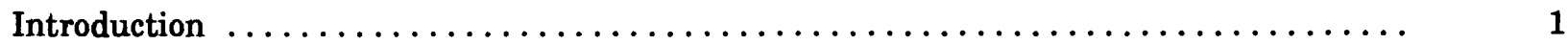

Physiological response to cold temperature $\ldots \ldots \ldots \ldots \ldots \ldots \ldots \ldots \ldots \ldots \ldots \ldots \ldots \ldots$

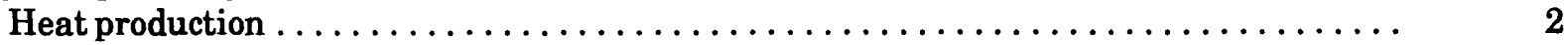

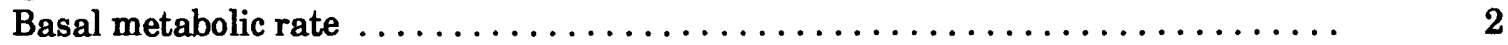

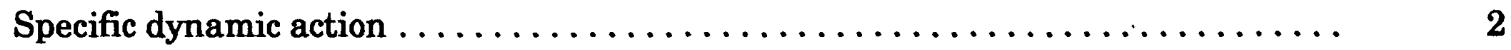

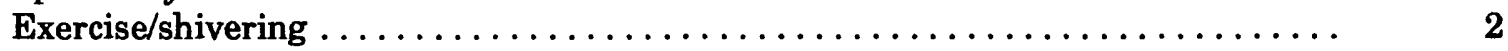

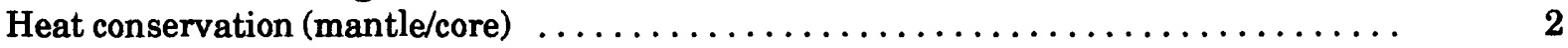

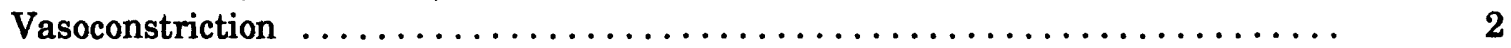

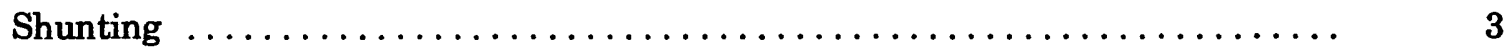

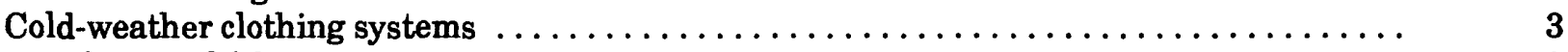

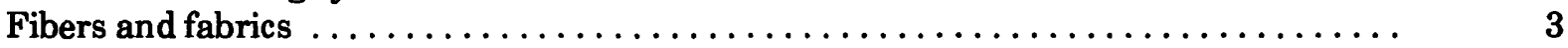

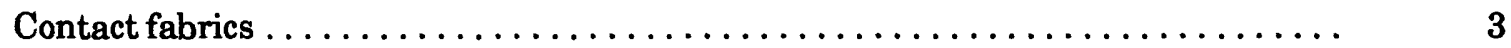

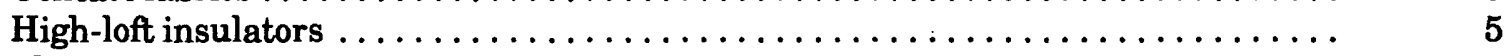

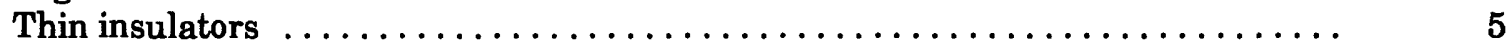

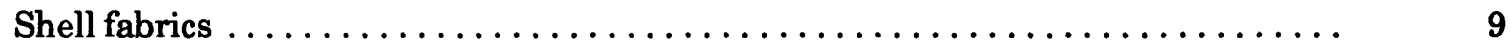

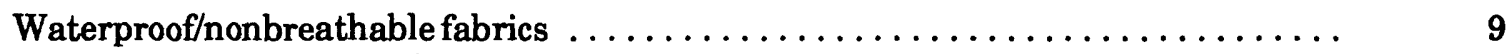

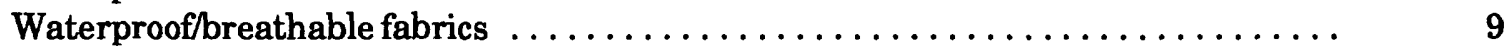

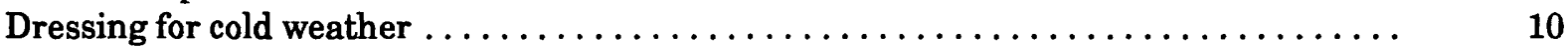

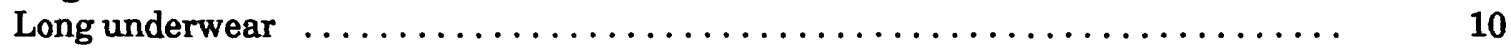

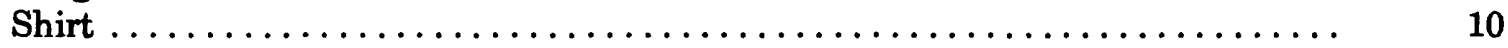

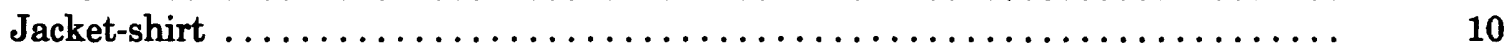

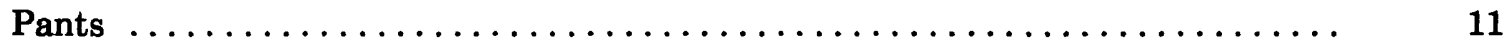

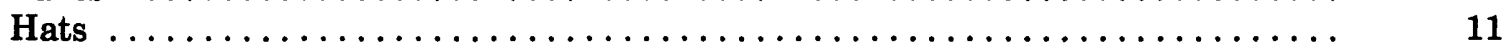

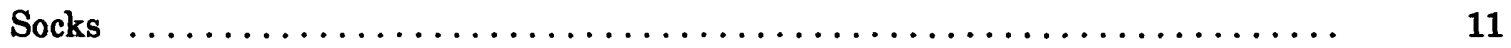

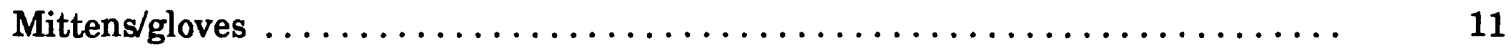

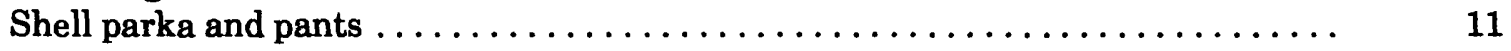

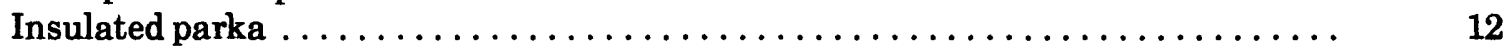

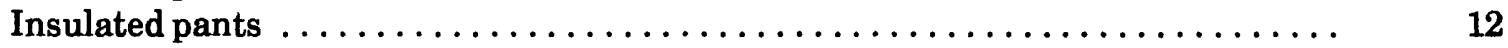

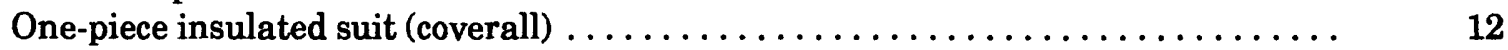

Arctic shorts . . . . . . . . . . 13

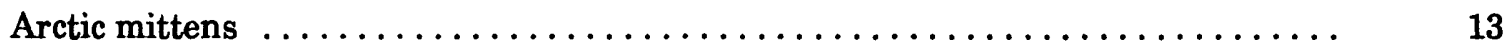

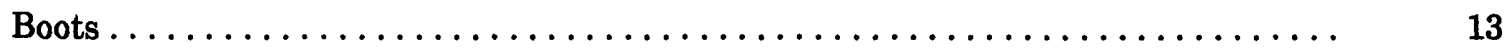

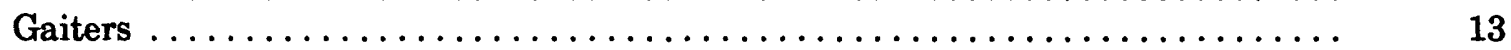

Recent developments in cold-weather clothing systems $\ldots \ldots \ldots \ldots \ldots \ldots \ldots \ldots \ldots \ldots \ldots$

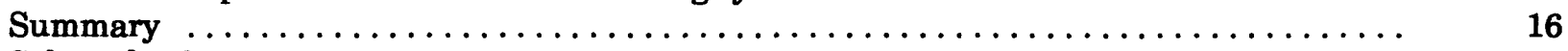

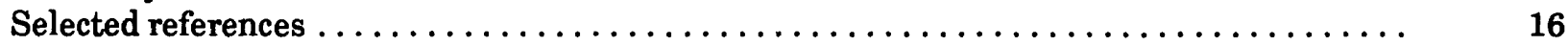




\section{ILLUSTRATIONS}

Figures 1-2.. Graphs of:

Page

1. Thermal conductance of selected fabrics $\ldots \ldots \ldots \ldots \ldots \ldots \ldots \ldots \ldots \ldots \ldots$

2. Relative warmth of selected fabrics having a thickness of 1 centimeter $\ldots \ldots \ldots \ldots .4$

Table

1. Moisture absorption of selected fabrics

Páge

2. Thickness comparison data ............

3. Clothing systems for cold weather ... 6

4. Wind-chill chart 


\title{
CONVERSION FACTORS AND ABBREVIATIONS
}

\section{Multiply}

inch (in.)
foot (ft)
yard (yd)
mile (mi)
square inch (in ${ }^{2}$ )
square foot $\left(\mathrm{ft}^{2}\right)$
square yard (yd $\mathrm{d}^{2}$ )
ounce (oz)
pound (lb)
ounce per square yard (oz/yd $\mathrm{y}^{2}$ )
ounce, fluid (fl. oz)
pint (pt)
quart (qt)
gallon (gal)

By

\section{Length}

25.40

0.3048

0.9144

1.609

Area

\subsection{2}

0.09290

0.8361

\section{Mass (Weight)}

\author{
28.35 \\ 0.4536 \\ 33.88
}

\section{Volume}

$\begin{array}{ll}0.02958 & \text { liter } \\ 0.4732 & \text { liter } \\ 0.9464 & \text { liter } \\ 3.785 & \text { liter }\end{array}$

\section{Temperature}

To obtain

\author{
millimeter \\ meter \\ meter \\ kilometer
}

square centimeter square meter square meter

\author{
gram \\ kilogram \\ grams per square meter
}

Temperature in degrees Fahrenheit $\left({ }^{\circ} \mathrm{F}\right)$ can be converted to degrees Celsius $\left({ }^{\circ} \mathrm{C}\right)$ as follows: ${ }^{\circ} \mathrm{C}=5 / 9\left({ }^{\circ} \mathrm{F}-32\right)$.

Temperature in degrees Celsius $\left({ }^{\circ} \mathrm{C}\right)$ can be converted to degrees Fahrenheit $\left({ }^{\circ} \mathrm{F}\right)$ as follows: ${ }^{\circ} \mathrm{F}=9 / 5\left({ }^{\circ} \mathrm{C}\right)+32$. 


\title{
A Primer on Clothing Systems for Cold-Weather Field Work
}

\author{
By Jon C. Denner
}

\begin{abstract}
Conducting field work in cold weather is a demanding task. The most important safety consideration for field personnel is to maintain normal body temperature and avoid hypothermia.

The human body adjusts to cold temperatures through different physiological processes. Heat production is enhanced by increases in the rates of basal metabolism, specific dynamic action, and physical exercise, and heat loss is reduced by vasoconstriction.

Physiological adaptations alone are inadequate to stop rapid heat loss in cold temperatures. Additional insulation in the form of cold-weather clothing is necessary to retain heat.

The most practical method of dressing for winter conditions is the layering system. Wearing multiple thin layers allows one to fine tune the insulation needed for different temperatures and activity levels. Recent developments in single layer, foam-filled cold-weather clothing systems are included in this revised edition.
\end{abstract}

\section{INTRODUCTION}

Field personnel working during the winter in the northern parts of the United States and in regions of high elevation are subject to unique and difficult environmental conditions. Temperatures can range from nearly $32{ }^{\circ} \mathrm{F}$ (degree Fahrenheit) (cold-wet conditions) to less than $-20^{\circ} \mathrm{F}$ (cold-dry conditions). Field work can involve periods of heavy exertion, such as carrying equipment to a work site, followed by periods of relative inactivity as when making stream discharge measurements or taking notes.

A person can work safely and productively under these conditions and avoid hypothermia, if a normal body temperature of $98.6^{\circ} \mathrm{F}$ is maintained. Hypothermia can be avoided primarily by the proper selection and intelligent use of cold-weather clothing systems. This report describes clothing systems that have been tested and successfully used by sportsmen, the U.S. Military, and by U.S. Geological Survey personnel. An initial section on physiology describes how the human body responds to cold temperature.

\section{PHYSIOLOGICAL RESPONSE TO COLD TEMPERATURE}

In order to maintain normal functioning of the human body, the internal temperature needs to be regulated to within about 1 degree above and below $98.6{ }^{\circ} \mathrm{F}$. Body temperature increases slightly during exercise and decreases slightly during sleep. For greatest comfort, the body prefers a warm, relatively moist environment. When the ambient temperature falls below this comfort level, cold-temperature induced stress occurs and a process called thermoregulation is used by the body to either increase heat output or to retain heat. 


\section{Heat Production}

\section{Basal Metabolic Rate}

Basal metabolic rate is the minimum energy required for bodily functions at rest. Exposure to cold over a long period can result in acclimatization so that the basal metabolic rate of the body increases and more "waste" heat is produced. This can happen over several weeks if enough daily exposure to cold temperatures is experienced. Once acclimatized, average winter temperatures are more easily tolerated. For example, $32^{\circ} \mathrm{F}$ feels cool in November but seems mild in January. It is advisable to acclimatize oneself to cold temperatures several weeks before an anticipated winter field trip.

\section{Specific Dynamic Action}

Specific dynamic action is a process by which the heat produced during digestion warms the body. Therefore, it is advisable to eat an appropriate breakfast before a day in the field. High-protein foods increase metabolism by the greatest amount. Some experts state that the Eskimos' (Inuit) ability to survive in the Arctic is based at least partly on a high-protein and fat diet (Forgey, 1985). High-protein snacks should be carried if long periods between meals are anticipated.

\section{Exercise/Shivering}

Exercise increases heat production dramatically. By exercising the large muscle groups of the legs, a chilled body can be rewarmed rapidly. Stamping boots and wiggling toes can delay chilling of the feet. Swinging the arms in a low position or making a fist and then relaxing the hand warms the fingers.

Shivering is an involuntary form of exercise that can generate heat for short periods. However, shivering is an early sign of hypothermia and should be prevented by wearing adequate layers of insulated clothing.

\section{Heat Conservation (Mantle/Core)}

The major organs deep in the body's core need to be maintained at a temperature near $98.6^{\circ} \mathrm{F}$. Lowering the temperature of the heart, lungs, kidneys, and other essential organs could result in death.

The body's mantle, which includes the skin, voluntary muscles such as the biceps and quadriceps, and the extremities, can tolerate a substantial lowering of temperature for several hours without damage. It is important, however, not to allow these tissues to actually freeze, or permanent damage from frostbite will occur. Heat conservation through vasoconstriction and shunting of the blood vessels occurs as the body responds to low temperatures. These processes are discussed in the following sections.

\section{Vasoconstriction}

Vasoconstriction is the process by which the small blood vessels of the mantle contract after exposure to cold air. This action forces blood into the warm core and away from the source of cold stress. If vasoconstriction fails to occur, cooled blood returns to the heart and other internal organs with damaging results.

Blood pressure rises as large amounts of blood are forced into the core. The body responds by reducing fluid volume through increased urine output. To counteract this dehydrating process, large amounts of fluids are needed to maintain the proper blood volume. Dehydration can lead to frostbite because smaller amounts of blood flow to the small vessels (capillaries) in the fingers and toes.

Nicotine is a strong vasoconstrictor and contributes to frostbite by reducing blood flow to the extremities. Nicotine also thickens the blood, thereby inhibiting blood flow through the smaller vessels.

Caffeine from coffee, tea, and cola drinks acts as a diuretic, causing fluid loss through frequent urination. During extended exposure to cold temperatures, then, it is important to drink non-caffeinated liquids in addition to caffeinated drinks to prevent dehydration.

Alcohol is a vasodilator and is dangerous when consumed in cold temperatures. Alcohol not only inter- 
feres with judgment and coordination but rapidly lowers the core temperature. After an alcoholic drink, the body feels pleasantly warm because the skin is flushed with blood from the core. This pleasant feeling soon passes, however, as cooled blood from the skin returns to the vital organs. Alcohol depresses the shivering response, thus eliminating one of the first signs of hypothermia. Alcohol also interferes with the brain's ability to control body temperature.

\section{Shunting}

If cold stress persists long enough, and if the vasoconstriction process is unable to protect the core, a more drastic response occurs to protect the body. Major vessels leading to the extremities will close down. This short circuiting or "shunting" will prevent all blood from reaching the extremities, causing fingers and toes to become numb. Frostbite is a real danger at this point so measures need to be taken immediately to restore blood flow to these appendages. Vigorous exercise rewarms the entire body, but the hand-foot shunt may not release immediately. Anyone who has come indoors with numb hands and feet knows how long and painful the restoration process takes.

If rewarming is not possible, the shunt is applied closer to the core. The situation becomes serious when blood flow is restricted at the knee or elbow, because the actual freezing of tissues in the lower arm and leg is then a distinct possibility.

Blood that travels to the head cannot be shunted for obvious reasons. Great amounts of heat will be lost from the head unless it is well insulated. A knit hat covered by a parka hood and possibly even a fur ruff with a face mask are needed in very cold temperatures to reduce heat loss from the head and neck. If the head is kept warm, adequate blood flow to the extremities is maintained as cold stress to the entire body is then reduced.

\section{COLD-WEATHER CLOTHING SYSTEMS}

When heat production and heat conservation within the body fail to maintain normal body temperature, a layer of insulation outside the body must be added to reduce heat loss. This insulating layer is clothing.
Cold-weather clothing applied in layers will allow proper adjustments to changes in air temperature and activity levels. The modern layering system is composed of a contact layer, an inner insulating layer, and an outer shell layer. An additional layer is needed in temperatures below $32^{\circ} \mathrm{F}$. This component generally is a thickly insulated outer garment.

\section{Fibers and Fabrics}

\section{Contact Fabrics}

Contact fabrics are thin fabrics worn close to the skin. They provide some insulation but the primary purpose of contact fabrics is to transfer moisture from the skin to the outermost layer of the clothing system. If a fabric is thicker than one eighth of an inch, it begins to act as a high-loft insulator because still air between the fibers becomes the major insulating medium. Contact fabrics generally are less than one eighth of an inch thick. There is minimal stagnant air present between the fibers, so the thermal-conductance properties of the fibor are an important consideration when selecting contact fabrics (fig. 1). Moisture absorption will affect the thermal-conductance characteristics of most fibers, so fibers that absorb minimal moisture generally should be chosen (table 1). Contact

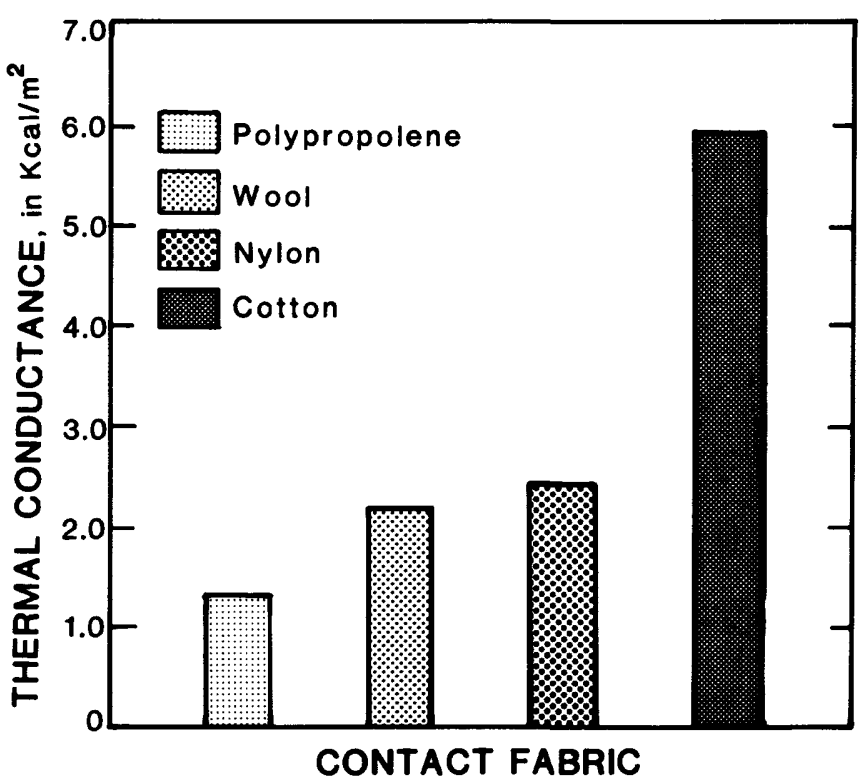

Figure 1.--Thermal conductance of selected fabrics [From Forgey, 1985, p.93]. 
fabrics are used in long underwear, shirts, pants, hats, socks, and mittens. Several commonly available contact fabrics are described below.

Table 1.--Moisture absorption of selected fabrics.

[All values are in percent of weight; Adapted from Shea, 1981].

Fabric Moisture absorption (percent)

Cotton

7

Wool

15

Nylon

5

Polyester

1

Polypropylene

0

because it absorbs moisture from the wearer and from the environment. Most cotton long underwear is constructed of a thickly woven fabric in which the major insulator is air. Cotton functions adequately until the air is replaced by water from sweat or precipitation. Once wet, cotton's insulating efficiency decreases dramatically and the fabric becomes a poor insulator. This condition presents minimal danger to the wearer if a warm shelter is nearby. Cotton fabric should not be worn, however, if rewarming and drying conditions are unavailable, as when working in remote areas.

Wool fibers are poor conductors of heat and, therefore, are good insulators. Wool can absorb large amounts of moisture, especially after the natural oils have been removed by repeated washings. Initially, wool appears to be a poor choice for outerwear because of its water-holding ability. Closer inspection of an individual fiber reveals a unique structure that makes wool an acceptable cold-weather fabric. When wet, wool retains some warmth as closed air cells within the wool fiber provide insulation even when the outer surface of the fiber is saturated with water. Wool fabric has been used as a contact fabric for centuries and its usefulness in cold climates throughout the world is well documented.

Nylon can absorb a moderate amount of moisture and is a poor conductor of heat. Nylon generally is blended with other fibers when worn close to the skin. This blend adds strength to weaker fabrics such as wool

Cotton has a high-moisture gain and is a poor contact insulator. Cotton fabric is very comfortable during warm weather when worn next to the skin because it is very breathable and conducts heat away from the body. Cotton is not desirable for cold-weather use

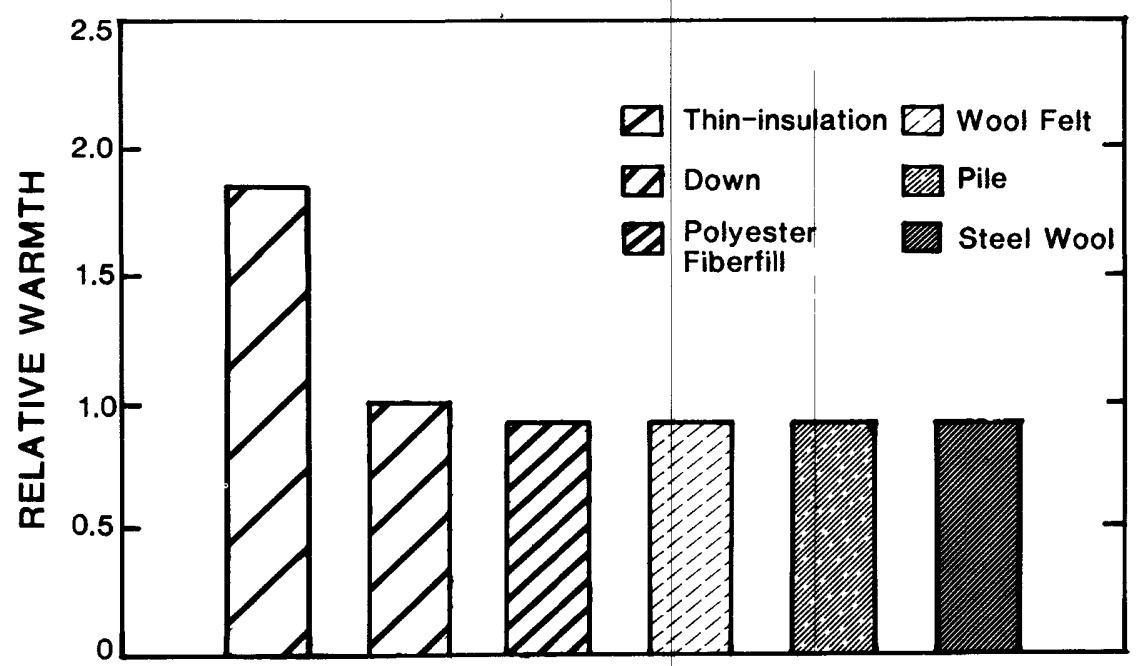

THICKNESS 1 CENTIMETER (0.39 INCHES)

Figure 2.--Relative warmth of selected fabrics having a thickness of 1 centimeter.

(From 3M Corp., 1978, p. 3). 
and is used to control fabric stretch. Nylon is primarily used in outer shell fabrics where a strong windproof layer is needed to contain goose or duck down or other insulation materials.

Polyester fibers absorb almost no moisture and are good insulators. Polyester is an acceptable substitute for wool for use in cold-wet conditions. This versatile fiber is woven into contact fabrics for use in long underwear, shirts, and pants. THERMAX ${ }^{1}$ is a polyester-based fabric that insulates when damp, is a poor conductor of heat, dries rapidly, and it can be used in long underwear as a wool substitute. POLARFLEECE or BUNTING $\left(10 \mathrm{oz} / \mathrm{yd}^{2}\right)$, POLARPLUS $\left(9 \mathrm{oz} / \mathrm{yd}^{2}\right)$, and POLARLITE $\left(7 \mathrm{oz} / \mathrm{yd}^{2}\right)$ are the polyester fabrics that can replace wool in shirts and pants. A warmer, but bulkier, fur-like fabric called pile $\left(13 \mathrm{oz} / \mathrm{yd}^{2}\right)$ is used in extremely cold temperatures. Polyester and cotton blends make tightlywoven windproof shell garments. When crimped, polyester is made in to high-loft fiberfill batts that are used to insulate sleeping bags and parkas. Polyester garments dry faster than those made of cotton or wool. Polyester garments seem to retain most of their insulating abilities even when wet; however, a completely saturated polyester garment would be cold to wear because the insulating air spaces between the fibers would be filled with water. Wet polyester garments can be wrung out and then worn without too much discomfort.

Polypropylene fiber absorbs no moisture and has a low conductance-of- heat value. Polypropylene is another acceptable wool substitute that is used primarily for long underwear, socks, and gloves. Performance of this fiber is comparable to that of polyester.

\section{High-loft Insulators}

High-loft insulators are thick, low-density materials that contain small spaces which effectively stop the movement of air that surrounds the body. Dry, stagnant air is an excellent insulator. Several types of high-loft insulators are described below.

Down is a natural material from the under-plumage of ducks and geese. For its weight, down is the most efficient insulator that is practical to use for clothing.
If properly laundered, down has a long, useful life expectancy. On the negative side, down is expensive and becomes useless as an insulator when wet. Some of the weight advantage is lost when down is fabricated into durable garments. The fragile nylon shell that contains the down pods needs to be covered with a heavy, wear-resistant fabric. Down is difficult to launder, but hand washing and line drying is probably the safest method.

Polyester fiberfill is a synthetic material that rivals down for use in insulated garments. Fiberfill is not as warm per unit weight as down but it has certain advantages over down. As mentioned previously, polyester fiberfill will provide some insulation when damp and it dries faster than down. The shell fabric used to encase fiberfill can be lightweight because a tear will not result in the loss of insulating material. Polyester fiberfill can be conveniently machine washed and dried on low heat.

Several brands of polyester fiberfill currently available have been field tested and perform satisfactorily when used in insulated clothing. One of these is POLARGUARD, a continuous-filament (long fiber) fiberfill mat. This material is very stable and it requires minimal quilt lines to hold it in position. By eliminating quilt lines or cold spots, a soft puffy-warm garment can be made. The other fiberfills, produced from the same fiber manufacturer, are HOLLOFIL and QUALLOFIL. These two fiberfills are short-staple fibers which are held together with resin and closely spaced quilt lines. These fiberfills are said to weigh less than POLARGUARD because of hollow spaces within the fiber shaft. HOLLOFIL contains one space and QUALLOFIL contains four spaces.

Polyester fiberfills are available in the following weights and approximate thicknesses: $6 \mathrm{oz} / \mathrm{yd}^{2}$ (ounces per square yard), $1.0 \mathrm{inch} ; 8 \mathrm{oz} / \mathrm{yd}^{2}, 1.25$ inches; $10 \mathrm{oz} / \mathrm{yd}^{2}, 1.5$ inches (table 2 and fig. 2 ).

\section{Thin Insulators}

Recently introduced thin insulating fibers have caused a minor revolution in the clothing industry. For decades all low-density materials were believed to have approximately the same insulating ability per

1 The use of brand names in this report is for identification purposes only and does not constitute endorsement by the U.S. Geological Survey. 
Table 2.--Thickness comparison data for high-loft insulation and contact fabrics

[ ${ }^{\circ}$ F, degree Fahrenheit. Data from U.S. Army, 69-74-CE].

\begin{tabular}{|c|c|c|}
\hline \multirow[b]{2}{*}{$\begin{array}{l}\text { Effective Temperature } \\
\qquad\left({ }^{\circ} \mathrm{F}\right)\end{array}$} & \multicolumn{2}{|c|}{$\begin{array}{l}\text { Thickness of insulation required for comfort }{ }^{1} \\
\text { (inches) }\end{array}$} \\
\hline & Light worl & Heavy work \\
\hline 40 & 0.8 & 0.20 \\
\hline 20 & 1.0 & .27 \\
\hline 0 & 1.3 & .35 \\
\hline-20 & 1.6 & .40 \\
\hline-40 & 1.9 & .48 \\
\hline
\end{tabular}

${ }^{1}$ These values are minimums; if in doubt add more thickness. The table does not apply to thin insulation.

equal thickness, be it goose down, fiberfill, shredded newspaper, or fine steel wool. The home-building industry was probably the first to develop products that seemingly violated this law. Several types of building insulation can be purchased that have a variety of insulating factors per equal thickness. For example, one inch of styrofoam wall insulation has a higher insulating factor than one inch of fiberglass wall insulation.

Fiber manufacturers have developed improved clothing insulators based on these new ideas. The fiber shafts used in the new thin insulators are of much smaller diameter than those found in high-loft fiberfills. Thin insulators require only half the thickness of high-loft fiberfill to provide the same degree of insulation (fig. 2). Microfilaments contained in the thin insulators seem to create a more efficient barrier against the movement of air. Thin insulators may also improve the reflection of radiant heat; reflecting more radiant heat back to the wearer. Thin insulators also provide some insulation when damp and they dry much faster than down.
Two brands of thin insulators are currently available that have been field tested and found to be useful in cold weather clothing. The first on the market was THINSULATE. The type used to insulate clothing is composed of polyolefin and polyester fibers. THINSULATE used in boots is 100 -percent polyolefin. The other brand of thin insulators is called THERMOLITE and is composed of specially modified polyester fibers. Thin insulators are produced in a variety of weights for use in winter clothing; they range from 1.3 $\mathrm{oz} / \mathrm{yd}^{2}$ to $9.7 \mathrm{oz} / \mathrm{yd}^{2}$. The new insulating materials are manufactured and advertised using metric values only.

The thin insulators appear to meet insulating needs better than the high-loft insulators (fig. 2). A thorough investigation of the advantages and disadvantages of each type of insulator is necessary to determine superiority. Goose down remains the best insulator per unit weight, however, thin-insulators provide the same insulating ability at almost half the thickness required by down, but the thin insulators weigh more than twice as much. 


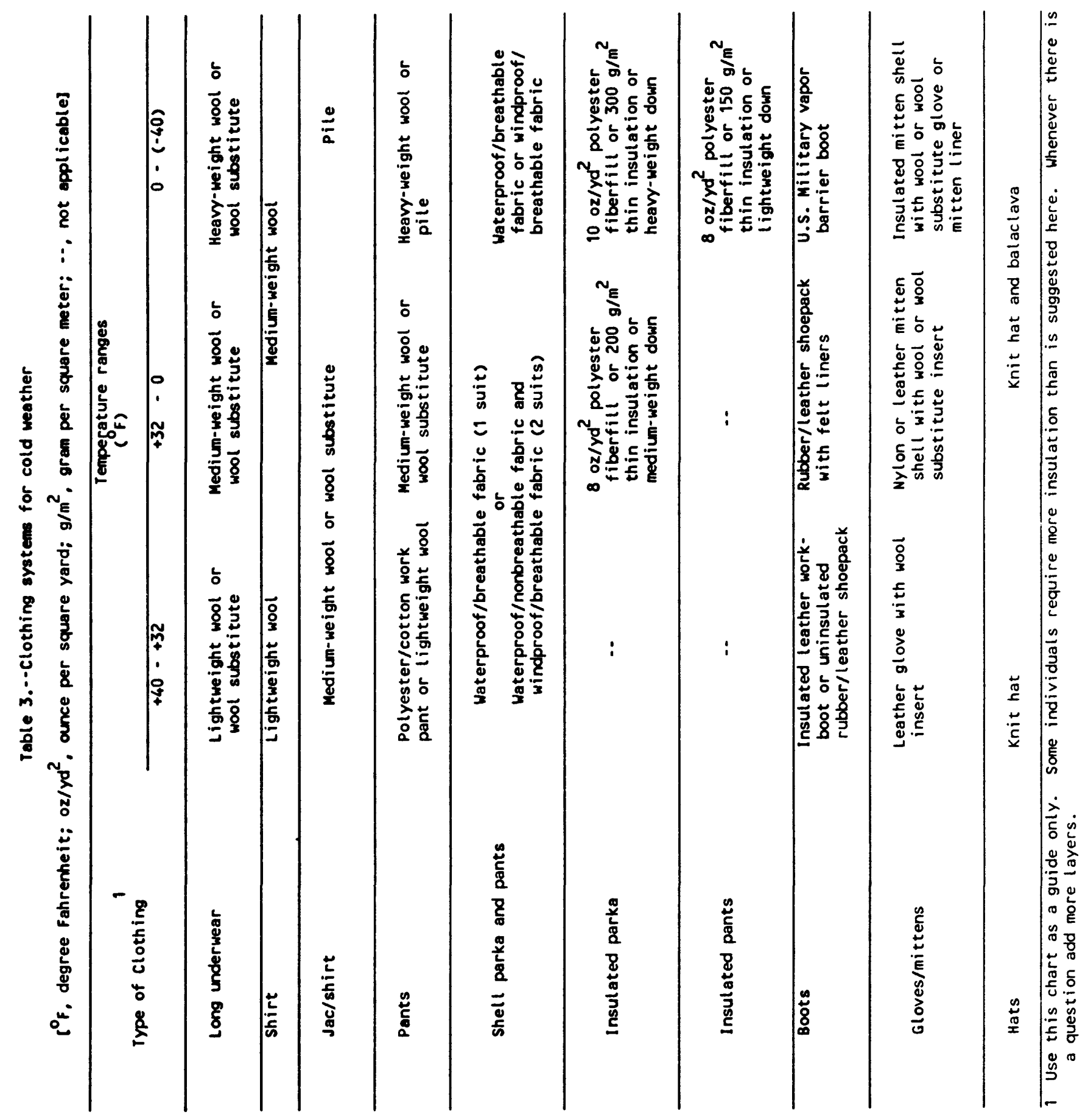




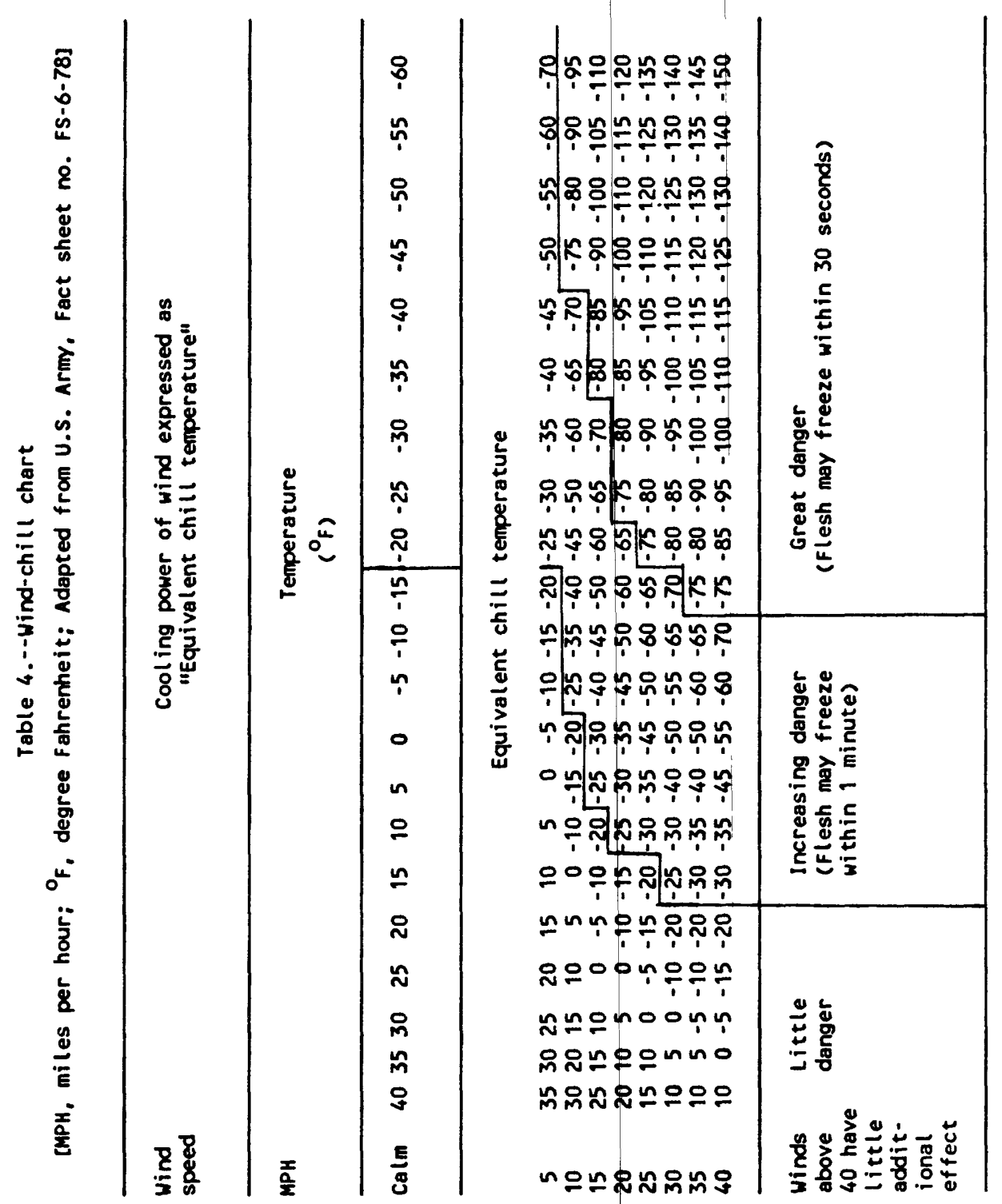


High-loft fiberfills, which are twice as thick as thin insulators, provide the same insulation and weigh about the same as the thin insulators. Thin insulators, therefore, have no weight advantage over high-loft insulators.

The major advantage of thin insulation is reduced bulk. This is particularly important in the manufacturing of insulated mittens, gloves, and boots. Insulated parkas and pants can be made with a slimmer profile which allows more freedom of movement when working in cramped spaces or getting in and out of vehicles.

Down, high-loft synthetic insulators, or thin insulators do not meet all needs under all conditions and for all uses; however, they are the best of the currently available materials for cold-weather gear. Each of these insulators, if incorporated into a well-designed parka, would perform satisfactorily, the differences between them being minor. Synthetic insulators should be chosen over down for use in a very damp climate. The synthetics, on the other hand, have a low melting point and may even burn when exposed to an open flame. A down parka with a natural-fiber shell may be a better alternative when working near an open flame for an extended period. Down garments compress into the smallest volume of any of the insulators which is important if the garments are to be carried in a backpack.

\section{Shell Fabrics}

Shell fabrics form the outer protective layer of the cold-weather system. Ideally, shell fabrics must be windproof, breathable, abrasion resistant, and water resistant. The shell garment generally is a separate layer that is worn over all the other layers. In some garments, however, the shell layer is permanently attached to other insulated layers.

Lightweight nylon fabrics can be used for inexpensive shells. Taffeta and ripstop are two popular lightweight nylon fabrics. They weigh approximately $2 \mathrm{oz} / \mathrm{yd}^{2}$.

Medium-weight nylon ( 3 to $5 \mathrm{oz} / \mathrm{yd}^{2}$ ) is more durable than those just described. Examples of this type of shell material are SUPPLEX and TASLAN--specially processed nylon fabrics that look and feel like cotton.

Natural and synthetic fibers are blended to make an abrasion-resistant and attractive fabric. Two exam- ples of this blended shell material are 60/40 cloth (cotton/nylon blend) and 65/35 cloth (polyester/cotton blend). These fabrics weigh about $5 \mathrm{oz} / \mathrm{yd}^{2}$.

\section{Waterproof/Nonbreathable Fabrics}

Various impermeable coatings can be applied to many fabrics to make a waterproof barrier. Heavy-weight raingear has traditionally been made by applying a rubber compound to cotton fabrics. More recently, neoprene has been applied to nylon fabrics to make a lighter garment with increased flexibility. The lightest rain fabric is nylon taffeta with a coating of polyurethane.

Nonbreathable fabrics generally are not worn over cold-weather garments. An impermeable layer traps moisture that is released from the body. This moisture also condenses in the other insulating layers that may be worn. A breathable-shell layer would be a better choice under most winter conditions. However, if rains are encountered in near-freezing temperatures, a waterproof garment may be necessary to prevent wetting of the inner layers. An ideal solution has not been conceived that resolves this dilemma in cold-wet conditions. If wool or wool-substitute garments are worn under raingear, normal body temperature can be maintained even though the inner layers are damp. If the rain persists long enough, and if the activity level is high enough to produce perspiration, complete saturation of the inner layers will occur. In this situation, the coated rain garment should be kept on because it will prevent wind penetration and reduce evaporative cooling.

\section{Waterproof/Breathable Fabrics}

The ideal rainwear fabric would be completely waterproof from the outside but would allow all the moisture from the inside to escape. Presently, a fabric that can do this under all conditions is not available, however, several fabric manufacturers are working on this goal. GORETEX is an example of a waterproof/breathable fabric.

Waterproof/breathable fabrics are characterized by tiny holes or pores that allow water vapor to pass through the fabric but prevent large water droplets from entering. Complete wetting of the outer fabric may reduce the breathability of the fabric. Also, cold rain could chill the shell fabric below the dew point so 
that moisture from the wearer will eventually condense in the inner layers. Oils and other contaminants seem to reduce the fabric's waterproofness. Waterproof/breathable fabrics are, however, windproof, offer superior water repellency, and function at least as well as uncoated fabrics under most conditions.

\section{Dressing for Cold Weather}

Experienced outdoor workers, out of necessity, assemble some sort of cold-weather system that works for them. Most individuals do not have the opportunity to test a wide variety of winter gear, primarily because of the high cost of those items. To use items directly from the "closet" seems appropriate; however, in extremely cold conditions these general-duty garments are inadequate. In average winter conditions these clothes could be adequate to use. Even under moderate conditions, however, professional outdoor workers need to purchase the most affordable yet comfortable and efficient system appropriate for them.

A person selecting clothing for use in a cold-weather layering system should consider the degree of insulation needed for various temperature ranges (tables 2 , 3 ) and the possible cooling effect of wind (table 4). Wind-chill factor is often misunderstood because the wind-chill chart is based on the cooling effect of wind on bare skin. The dangers of wind-chill can be reduced by wearing windproof fabric over most of the body. In below zero temperatures, however, one must be aware of the potential for frostbite of the exposed face and hands in windy weather.

\section{Long Underwear}

Choosing the proper fabric to wear next to the skin contributes greatly to warmth and comfort. For reasons previously explained, avoid cotton long underwear unless a dependable heated shelter is nearby. Wool long underwear is desirable but is harder to find at retail outlets. Some people dislike the scratchy feeling associated with wool, but high-quality wool reduces this problem to an acceptable level. Wool underwear provides some warmth, even when damp, stretches well, and is durable. Laundering wool is a problem because shrinkage can occur.

Several wool substitutes have been developed that rival wool. These synthetic fabrics seem to wick mois- ture from the skin. Medium-weight fabric (6 oz/yd ${ }^{2}$ ) is an appropriate all-around choice. Lighter fabric is available for early winter or for people who will be very active. Heavier fabric is available for extreme conditions or for low-energy activities.

A light wool sweater could be used as an inexpensive long-underwear top. If worn under a roomy wool shirt, the sweater offers exceptional warmth and breathability.

\section{Shirt}

Cotton shirts should be avoided except for the driest climates. A lightweight wool $\left(10 \mathrm{oz} / \mathrm{yd}^{2}\right)$ shirt is a safer choice because wool is warm when damp, durable, and stretches easily. Wool shirts need to be bought in the proper size, which means roomy. People 5'11" or taller should buy tall sizes for additional sleeve and tail length.

Turtle-neck shirts are popular because they stretch easily and add substantial insulation to the neck area. Turtle necks, however, interfere with the layering principle because of the lack of ventilation provided at the throat. A short zipper is needed to correct this problem.

\section{Jacket-Shirt}

In colder conditions, a wool jacket-shirt can be worn over the lightweight shirt and long-underwear top. A medium-weight wool fabric (13-16 oz/yd $\left.\mathrm{d}^{2}\right)$ is satisfactory for this use. The jacket-shirt needs to be sized large enough to fit comfortably over the other layers so that freedom of movement is not impaired. Wool sweaters have traditionally occupied this layer and can be successfully used, but sweaters are less durable than the tightly woven jacket-shirt.

Synthetic substitutes are now available which can replace wool. These wool substitutes are lighter in weight but just as warm as wool. Three polyester fabrics can be used for this layer--POLARFLEECE also called BUNTING, POLARPLUS, and POLARLITE. Pile is used in extremely cold temperatures. 
Blue jeans and other cotton pants should to be avoided. Polyester-cotton work pants are acceptable for cool temperatures and they are economical. Work pants worn over wool or wool-substitute long underwear produces the warmest system. Medium-weight wool pants, such as the U.S. Military version from surplus, are warm and durable. In extreme conditions, heavy-wool pants ( 20 to $24 \mathrm{oz} / \mathrm{yd}^{2}$ ) might be needed.

Synthetic substitutes are now available that replace wool. The polyester fabrics mentioned in the jacketshirt section are also used to make acceptable pants. POLARPLUS, POLARFLEECE, and $11 \mathrm{oz} / \mathrm{yd}^{2}$ pile may be used successfully for pants.

\section{Hats}

A warm hat is necessary because the head releases great amounts of heat if it is not properly insulated. The least expensive and perhaps the most satisfactory headgear is the common knit hat. This hat needs to be made of wool or a wool substitute and long enough to come down over the ears. A balaclava is similar to the knit hat, but it is long enough to cover the face and neck and provides more insulation. For extreme conditions, a warmer balaclava can be made of pile fabric.

Insulated, baseball-style caps are also available. Some have earflaps and other features that may prove valuable to the wearer.

\section{Socks}

Cotton socks are not desirable for use in cold weather. Wool or wool-substitute socks are the best choice because they provide some warmth when damp. There is a limit to the number of sock layers that can be worn on the foot. Forcing a foot with multiple layers of socks into an undersized boot defeats the purpose of warm socks. If too many socks are worn, blood flow to the foot is reduced causing cold feet.
Wool or wool-substitute gloves worn inside leather work gloves are acceptable in cool temperatures. In cold weather, mittens generally are used instead of gloves because mittens are warmer. Mittens have less surface area to dissipate heat than gloves and the fingers share heat when held close together. Wool mittens can be worn inside nylon or leather shells. Nylon shells are preferred under most conditions because nylon absorbs minimal moisture. The nylonshell wool-mitten system should be easy to put on and remove. A properly designed mitten has a gauntlet or extended cuff with a flared opening that is wide enough to go over the various layers of clothing at the wrist. The hand is simply inserted and the mitten cuff (gauntlet) readily slips over the bulky layers at the wrist. The mitten top is then closed with a VELCRO strap or other device to seal the opening. This step generally is not necessary except during extreme conditions.

When working with delicate instruments or when attempting to write it is helpful to wear a lightweight glove under the mitten system. This glove provides warmth for short periods when the hand is exposed and it prevents contact with metal objects, reducing the risk of frostbite.

\section{Shell Parka and Pants}

A weather-resistant shell is needed to cover the openweave insulating layers. The primary purpose of a shell garment is to provide wind protection so the insulating layers underneath function properly.

The lightest fabric used for the shell layer is nylon taffeta or ripstop. Parka and pants made of this lightweight nylon can be compressed to fit into a pocket or small backpack. For increased durability heavier nylon or a blended fabric could be used.

The shell parka should have a hood, several pockets with sealable flaps, and a ventilating zipper covered by a flap closure. The cuff should close over the wrist with VELCRO, snaps, or moderately loose elastic.

The shell pants can be simple pull-on style with no zipper or with full- length side zippers that open down the leg. Full-length side zippers allow easy on-off procedures when wearing skis or snowshoes. 
If rain or wet snow is encountered, the outer breathable-shell layer would be replaced by waterproof rainwear.

A popular shell parka, composed of blended fabric, has a wool lining permanently sewn into the parka. This combination is successful in that it offers insulation and wind protection in one garment, but it lacks versatility over a broad temperature range. A solution might be to wear a separate wool jacket-shirt covered by a shell parka. Versatility is the main advantage of the multi-layer system. Layers of clothing may be added or removed to meet the changing weather conditions and activity levels.

\section{Insulated Parka}

Several layers of wool and a windproof shell would provide enough insulation to keep the average person warm for a long time in temperatures down to $32^{\circ} \mathrm{F}$. If that same person were to exercise excessively, this clothing system would remain comfortable to $0{ }^{\circ} \mathrm{F}$. This is an estimate because too many variables, such as wind, individual metabolism, and humidity, are involved to accurately rate clothing systems. When temperatures drop below freezing, it is necessary to add a greater amount of insulation than is provided by thin inner layers. Some outdoor workers prefer to add more thin layers, such as wool shirts, cotton sweatshirts, and denim jackets. This technique does add warmth, but decreases efficiency because of the additional weight. Multiple dense layers can also restrict freedom of movement, which drains energy. A successful solution is to use a low-density insulator in a properly designed parka.

An insulated parka typically has an outer breathable shell, a lining of lightweight nylon, and a fill material of down, fiberfill, or thin insulation. Down parkas are quilted to hold the down in place. To add durability and warmth some down parkas have an additional third shell layer sewn over the quilted-down component. Many fiberfill parkas are constructed in a similar style to down parkas. To save weight, some synthetic parkas dispense with the outer more-durable third layer because a minor tear is not critical. Unlike down, fiberfill and thin-insulators will stay in place even if the shell is damaged.

A properly designed parka has a hood, extends to the hips, and fits loosely over the inner wool layers. The front should open with a heavy-duty nylon zipper that generally is covered by a flap that closes with snaps or VELCRO. This flap keeps out wind and snow and it acts as a back-up if the zipper fails. Ample pocket space is a convenience. The cuffs should close around the wrist with a VELCRO flap or snaps and elastic.

A properly designed parka hood will cover other headgear with room to spare. The sides of the hood need to project out to protect the face from wind. Fur ruffs are rarely found on parka hoods today, but if one is added, it will greatly increase warm th around the face and neck. A scarf is useful in sealing the openings that occur in the neck area. In extreme conditions, when a face-mask is sometimes worn, the parka hood should be large enough to allow for the scarf. Cordlocks on drawcords and nylon loops on zipper pulls allow for easy opening and closing, even while wearing mittens

Select a parka with enough insulation for protection at the lowest temperatures anticipated. During periods of exertion, the inner wool layers will provide enough insulation so that the parka may be set aside or otherwise stowed. The insulated parka is then immediately put on when exertion ends.

\section{Insulated Pants}

Construction and features of insulated pants are similar to those described for the parka. The amount of insulation, however, is less than that required for the parka. If heavy wool or pile are chosen for the inner layer an insulated outer layer may not be needed. Insulation around the leg contributes to foot warmth. The femoral artery passes near the skin surface at the inner thigh, and large amounts of heat are lost if this area is not adequately insulated.

Insulated pants should have full-length side zippers to avoid removal of boots, skis, or snowshoes when donning or removing the pants. During periods of exertion the insulated pants are removed to avoid overheating.

\section{One-Piece Insulated Suit (Coverall)}

The one-piece insulated suit or coverall may be substituted for the insulated parka and pants in certain situations. The insulated coverall is designed primarily for snowmobiling and other activities not requiring extreme physical exertion. It is comfortable to wear because constriction at the waist is eliminated, as no belt is needed. The one-piece suit generally is light- 
weight and less expensive than the two-piece parka and pants system. The insulated coverall, however, lacks the flexibility to allow for adjustment over a range of temperatures and activity levels. Another disadvantage is the necessity of removing the entire suit to eliminate body wastes--dropseats are available only on some military surplus suits and expensive mountaineering garments.

\section{Arctic Shorts}

These specialized pants are useful for people who need to wear chest-waders and stand in icy cold water for long periods. Arctic shorts are made by cutting off the lower portion of insulated pants just above the knee. The shorts are worn over wool pants and under the waders, and provide insulation around the thighs, abdomen, and kidney area, thus delaying the onset of hypothermia. The lower part of the pant leg is cut off to reduce bulk around the calf when wearing chest waders.

\section{Arctic Mittens}

Arctic mittens are similar to the standard mitten described previously, except that the shell portion of the arctic version is insulated with down, fiberfill, or thin-insulation. In extreme conditions arctic mittens may be needed, especially by snowmobilers. The gauntlet adds extra insulation to a critical area around the wrist. Arteries pass close to the skin surface and heat loss from the blood is rapid unless properly insulated.

\section{Boots}

For cool weather a waterproof leather boot, with closed-cell foam insulation and a lug sole, is used by many outdoor workers. A combination leather/fabric boot is available that also is satisfactory for cool conditions. This boot is insulated with thin-insulation and lined with a waterproof/breathable fabric.

Footwear appropriate for working in wet conditions is the rubber-bottom leather-top boot. This uninsulated boot is lightweight and offers warmth against freezing temperatures when worn with two pairs of wool socks. The soles are slick, however, and not designed for steep terrain.
When temperatures drop to and remain below $32{ }^{\circ} \mathrm{F}$ and stay there, many workers in northern latitudes switch to rubber-bottom leather-top felt-lined shoepacks. These boots and extra liners are available from many retail outlets and are economical. They may be purchased with a lug sole to avoid the traction problem. The felt liners absorb moisture from the foot and become damp and cold. If spare liners are carried, they may be exchanged for the damp liners when necessary. The damp liners will dry overnight if placed near a heat source, and can be used again the next day.

An alternative to switching felt liners is to add a vapor-barrier liner to prevent moisture from reaching the felt liner. A plastic bread bag or a commercially made vapor-barrier sock is placed over one thin sock. Another heavier sock is pulled on over the vapor-barrier liner. The foot is then placed into the felt liner inside the boot. Moisture from the foot is trapped between the vapor-barrier liner and the skin surface. The foot and thin sock are damp but warm because the insulating felt liner and heavy sock are dry. No moisture enters from the outside because the rubber boot is waterproof. This procedure is successful if no means for drying the felt liner is available at the end of the day.

Another useful boot for extremely cold temperatures is the U.S. Military vapor-barrier boot. This boot is constructed of felt sealed between two impermeable layers of rubber. Moisture does not penetrate and degrade the insulation unless the rubber covering is torn. Only one pair of socks needs to be worn inside this boot. As the socks will become damp it is advisable to carry spares. For someone working in a remote area these boots offer a measure of security against frostbite.

\section{Gaiters}

Gaiters are fabric ankle coverings designed to prevent snow from entering boots and to keep the lower pant leg dry. The top sleeve-like part generally is made of uncoated nylon or blended fabric. The bottom part, around the boot, is constructed of heavier, waterproof nylon. A zipper, with a flap cover that can be closed with snaps or VELCRO, is useful in getting the gaiter on and off. In deep snow, gaiters are almost essential. 


\section{RECENT DEVELOPMENTS IN COLD- WEATHER CLOTHING SYSTEMS}

A new concept in cold-weather clothing, featuring polyurethane foam insulation, was field tested in northern Vermont. The Office of Surface Water provided funding to evaluate clothing that incorporates recent advances in textile and material technology. Efficient cold-weather clothing systems can reduce the potential risk of hypothermia, while increasing the comfort and safety of field personnel in harsh winter environments.

Conventional cold-weather clothing systems consist of multiple layers of garments. A typical ensemble can include wool or synthetic long underwear, wool or wool-substitute shirts and pants, fiberfill or insulated outerwear of goose down, and a weather-resistant outer shell. The advantage of this system is that the layers can be added or removed to meet the everchanging demands of weather and activity levels. Moisture accumulation in clothing is a serious problem in cold environments because it can reduce a fabric's ability to insulate. The multilayer system reduces the problem of moisture accumulation because layers can be removed to prevent overheating and waterproof shells can be worn to decrease moisture penetration from the environment.

Foam-insulated clothing differs from the multilayer system in that it consists of one layer, or monolayer. The entire outfit (hat, parka, pants, mittens, and boots) is made of open-cell polyurethane foam lined with a highly breathable mesh fabric on the surface and covered with a windproof (not waterproof) shell on the outer surface. The foam garments can be worn next to the skin; long underwear and other inner layers are unnecessary. Unlike the multilayer system, the complete monolayer is worn at all times. The clothing is selectively ventilated with zippers that can be opened to preclude overheating. The skin is cooled most efficiently when it is not covered by inner-fabric layers such as long underwear. There is no need to remove layers to meet variations in air temperature and activity levels. Moisture transfer through the foam is rapid and, even if the foam becomes damp, it loses little of its insulating properties. The low-density polyurethane foam is an efficient insulator. The foam used in all components (except the boots) is 1 -in. thick; the boots have a lining that is 1.75 -in. thick.

The foam-insulated clothing was tested during routine field activities. Weather conditions varied widely, with temperatures ranging from 35 to $-22{ }^{\circ} \mathrm{F}$; snowfall was frequent and there were occasional rains. Field work included servicing gaging stations and (or) meteorological sites. Thermal efficiency was evaluated during the prolonged periods of inactivity during the taking of discharge measurements from ice cover. Ventilating ability was evaluated during extensive snowshoeing and hiking to field sites.

The parka consists of a 1-in. polyurethane-foam liner that is attached with snaps to a windproof shell. The liner closes in the front with snaps, and a nylon belt at the waist can be tightened to prevent drafts. The open-weave fabric covering the foam facilitates moisture transfer. The smooth fabric on the inner surface is comfortable even against bare skin. A removable shell garment covers the foam liner. It has conventional ski-parka styling with a full-front zipper. Other features include two hand-warming pockets, two patch pockets at the chest, VELCRO cuff closures, and a zipper flap. The tall collar comes up to nose-level and is surrounded by a hood. The hood is insulated with $0.5 \mathrm{in}$. of foam, closes under the chin with VEL$\mathrm{CRO}$, and has drawcords for tightening the face opening.

Most parkas intended for use in extreme cold are bulky and the foam outfit was no exception. A consistent $1.0 \mathrm{in}$. of loft is provided throughout, a condition not always found in conventional parkas because of cold spots at quilt lines and seams. Despite its bulk, the foam parka offered adequate freedom of movement, particularly when no undergarments were worn. However, the bulk and thickness can cause problems while driving a vehicle; an individual's maneuverability may be impaired. One solution is to wear conventional clothing while driving and then change into the foam clothing at the work site.

Ventiliation is enhanced by opening the zipper on the shell, rolling up the sleeves, and dropping the hood. Any breezes can then penetrate the foam liner and carry off excess heat and moisture. In mild weather, the shell is removed and stored in the parka hood.

Materials used in the insulated pants are the same as those for the parka. The pants are held up by padded suspenders. There are zippers along the hips for ventilation and there is a convenient drop-seat feature. Additional ventilation is provided by zippers at the inner thigh. These openings promote rapid exchange of air during periods of exertion.

The pants' bulk does not restrict mobility, particularly when worn directly over the skin. Long underwear or 
wool pants, when layered under the foam, not only stifle ventilation but can cause fabric drag.

The boots are amply insulated with 1.75 in. of polyurethane foam. Two insoles are placed underneath the foam liner; one is made of rigid closed-cell foam that provides extra insulation, and the other is made of plastic mesh that promotes moisture exchange. The removable foam liner and insoles are inserted into an outer shell of nylon fabric in the upper part with a hard plastic welt and sole. The boots are very large because of the great thickness of insulation; but they can be adjusted for a good fit by use of an elaborate system of straps.

The complete boot system has a total weight approximately the same as the U.S. Military vapor-barrier boot. When the boots are worn for long distance hiking, their excessive weight can contribute to fatigue. Although the principal materials comprising the boot are lightweight, a fiberglass ankle support adds considerable weight. Due to the large size of the footwear, it is difficult to drive a vehicle when wearing the boots. Wearing standard footwear while driving is recommended.

The boots are intended for use in dry-cold environments, but they were found to be useful over a broad range in temperature. Unlike rubber footwear, the foam-insulated boot system was not designed to be waterproof. However, the sole and welt are waterproof, and sufficient freeboard exists to permit use in slushy snow or shallow water conditions. In one test, the boots were immersed intentionally, the liners wrung out, and the boots worn for several hours. Despite the dampness, the foam insulation protected the wearer's feet even in severe temperatures.

The mittens are the gauntlet type, with 1-in. foam insulation. Although the mittens are too bulky to wear for delicate work, they are flexible enough to wear for such tasks as ice chiseling and holding icemeter rods. The wide gauntlet opening makes them easy to take on and off. The mitten back is covered with soft pile fabric, which can be used for warming the face in severe conditions. VELCRO patches enable temporary attachment of the mitten to complementary sites on the parka. This feature provides a convenient means of holding mittens when they are removed for short periods. There also are pockets under the pile-backing material of the mittens. These hold lightweight mitten shells and sheer nylon liner gloves. These items are worn when the thick outer mittens are not needed or when manual dexterity is called for. The mittens can be attached to the parka with a lanyard to prevent loss.

A foam-lined cap with earflaps and brim may be used alone or under the parka hood. The cap is covered with nylon fabric and held securely with an elastic strap.

An optional outer parka, with $0.5 \mathrm{in}$. of foam insulation, is available for use in severe cold. This garment was not available for the field test, nor was it felt necessary for use in typical winter conditions in northern Vermont. Where climatic extremes necessitate, such as in the Arctic, this additional insulation may be required.

Preliminary results are encouraging and further field testing is ongoing. One area of interest is experimentation with various thicknesses of foam for different climates and applications. For example, in less severe climates, it may be found that thinner foam may be adequate. In that way, the superior insulating and moisture-handling qualities of foam will be retained and the problems caused by bulk will be reduced.

The monolayer system affords a number of advantages including the following:

- Insulation is efficient.

- Moisture does not degrade insulation so there is less concern about dampness.

- Clothing does not need extensive drying time and can be worn indefinitely.

- Clothing can be slept in if an emergency survival situation should arise.

- Convenience is gained by not having to add or remove garments at frequent intervals.

- Clothing is worn, not carried.

The system, however carries certain disadvantages including the following:

- Clothing is bulky.

- Clothing can be energy draining on long hikes because of the bulky, heavyweight footwear.

- Clothing can bring on overheating in mild weather.

- Boots are too large to wear when driving vehicles. 


\section{SUMMARY}

Proper clothing worn in layers is a practical solution to the problem of staying warm in cold temperatures. Effective insulation, combined with heat-generating physiological processes, form an effective defense against a harsh winter environment.

The layering system begins with a contact fabric. Wool long underwear is the traditional garment of choice. Recently, synthetic fibers such as polypropylene have emerged as acceptable fabric substitutes.

Wool shirts, pants, socks, and mittens composed the inner insulating layer for centuries. Acceptable synthetic substitutes for these items now rival wool.

The outer or shell layer protects the inner layers from wind and rain. Tightly woven nylon and cotton/synthetic blends are windproof. Coated fabrics are waterproof but cause condensation. New waterproof/breathable fabrics eliminate some of the condensation problems.

Lower temperatures demand that additional insulation be worn over the other layers. Goose down and high-loft synthetic insulators are used to insulate quality parkas, pants, and mittens. Recently introduced thin-insulators provide adequate insulation in thin layers.

Working in moderate winter weather is not difficult if one is acclimatized, well fed, and adequately dressed; however, coping with extreme conditions can be a challenging experience. Field personnel can work safely and with minimal discomfort, even in low temperatures, if properly equipped and if good judgment is used. Tasks successfully completed in adverse weather impart a feeling of triumph over the elements.

A new concept in cold-weather clothing, a single-layer garment with polyurethane-foam insulating material, was field tested in northern Vermont. The results of a two-year field evaluation were favorable. Use of this clothing system can increase the comfort level of people working in harsh field conditions.

\section{SELECTED REFERENCES}

Daniels, J.A., 1979, Winter Hiking and Camping (2nd ed.): Glens Falls, N.Y., Adirondack Mountain Club, p. 45-65.

Forgey, W.W., 1985, Hypothermia - Death by Exposure: Merrillville, Ind., ICS Books, Inc., p. 19-32, 88-102.

Petzoldt, Paul, and Ringholz, R.C., 1984, The New Wilderness Handbook (2nd ed.): New York, W. W. Norton and Co., lnc., p. 69-87.

Roberts, Harry, 1977, Movin' On - Equipment and Techniques for Winter Hikers: Washington, D.C., Stone Wall Press, Inc., p. 65-84.

Rutstrum, Calvin, 1973, The New Way of the Wilderness (2nd ed.): New York, The Macmillan Co., p. 83-89, 165-172.

Shea, Lee, 1981, Textile Terminology for the Outdoors: Lander, Wyo., National Outdoor Leadership School, 4 p.

3M Corporation, 1978, Technical Bulletin, Manufacturer's Fact Sheet: St. Paul, Minn., 3 p.

U.S. Army, 1978, Fact Sheet: Natick, Mass., Natick Research and Development Center, no. FS-6-78, 9 p.

----1974, Technical Report: Natick, Mass., Natick Research and Development Center, no. 69-74CE, 3 p.

-U.S COVERNMENT PRINTINC OFFICE $1993.701-232180009$ 